\title{
Removal of copper from industrial sludge by traditional and microwave acid extraction
}

\author{
Chao-Yin Kuo ${ }^{\mathrm{a}}$, Chung-Hsin $\mathrm{Wu}^{\mathrm{b}, *}$, Shang-Lien Lo ${ }^{\mathrm{c}}$

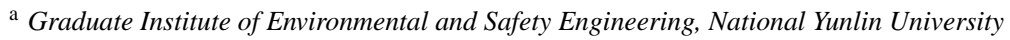 \\ of Science and Technology, Taiwan, ROC \\ ${ }^{\mathrm{b}}$ Department of Environmental Engineering and Health, Yuanpei University of Science and Technology, \\ 306 Yuanpei Street, Hsinchu, Taiwan, ROC \\ ${ }^{c}$ Graduate Institute of Environmental Engineering, National Taiwan University, Taipei 106, Taiwan, ROC
}

Received 19 October 2004; received in revised form 17 January 2005; accepted 24 January 2005

\begin{abstract}
This work elucidates the removal of copper from industrial sludge by traditional and microwave acid extraction. The effects of acid concentration, extraction time, sludge particle size and solid/liquid (S/L) ratio on copper removal efficiency were evaluated. Leaching with more concentrated acid yielded greater copper content from the industrial sludge. The experimental findings reveal that the most economical traditional extraction conditions were the use of $1 \mathrm{~N}$ sulfuric or nitric acid for $60 \mathrm{~min}$ at an S/L ratio of 1/20; however, at an S/L ratio of $1 / 6$, the extraction time needed to achieve the same copper removal efficiency was increased to $36 \mathrm{~h}$. Increasing the microwave power and reducing the S/L ratio increased the copper extraction efficiency and the effect in the larger S/L ratio system was more significant. A comparison of the results of microwave-assisted (microwave only) and microwave-enhanced (microwave with addition of active carbon) acid extraction demonstrated that under both conditions, $\mathrm{S} / \mathrm{L}$ ratio $=1 / 6$ and 1/20; adding active carbon shortened the extraction time required to achieve $80 \%$ copper extraction efficiency from 20 to $10 \mathrm{~min}$. These experimental results indicate that the most important factors that most strongly affected microwave acid extraction were the addition of a microwave absorber, the microwave power input and the $\mathrm{S} / \mathrm{L}$ ratio. The sludge particle size did not significantly affect the copper extraction. The results reveal that sulfuric acid was an effective extractant and that the copper fraction in the extracted sludge shifted from being mostly bound to the Fe-Mn oxides and organic matter, to being mostly bound to organic matter and remaining as a residue during acid extraction.
\end{abstract}

(C) 2005 Elsevier B.V. All rights reserved.

Keywords: Copper; Microwave; Acid extraction; Industrial sludge; Sequential extraction procedures

\section{Introduction}

Industrial development has led to the generation of more and more industrial waste during production processes. One of the most serious related problems is the generation of industrial sludge that contains various toxic metals. Industrial sludge can normally be treated by vitrification, cement solidification and extraction using acids or solvents; however, vitrification and cement solidification have numerous disadvan-

\footnotetext{
* Corresponding author. Fax: +886 35385353.

E-mail address: chwu@mail.yust.edu.tw (C.-H. Wu).
}

tages. Vitrification involves relatively high cost of treatment and construction. In cement solidification, a large amount of cement is required to make the cemented solid sufficiently strong and prevent the re-leaching of heavy metals caused by the breaking of the solid. The cost of disposing of cemented sludge that contains toxic metals has been increasing exponentially and the number of landfills that can receive such waste in Taiwan has been falling. Strong economic reasons exist for considering the use of a removal system instead. The extraction process is environmentally and economically attractive because it can detoxify industrial sludge and remove valuable metals for reuse. Various studies have investigated 
the use of acids and solvents to remove metals from solid waste, such as in extraction using perchloride, nitric and sulfuric acids [1-4].

Ahmed et al. [5] found that over $70 \%$ of $\mathrm{Co}, \mathrm{Fe}$ and $\mathrm{Zn}$ could be extracted from smelter slag using aqueous sulfur dioxide, and that the degree of extraction was improved by increasing the concentration of sulfur dioxide and the temperature. In conventional thermal processing, energy is transferred to the material by the convection, conduction and radiation of heat from the surface of the material. In contrast, microwave energy is delivered directly to materials via molecular interactions with the electromagnetic field. This difference in the manner in which energy is delivered is responsible for the numerous potential advantages in using microwaves to extract industrial sludge. Microwave heating is faster and so supports faster dissolution than does conventional heating. Microwave energy has the potential to be used in metal recovery operations, such as heating, drying, leaching, roasting/smelting and waste management [6]. Rapid solvent extraction [7] and the fast wet dissolution of various types of solid samples $[8,9]$ are some of the most well known microwave applications. Gan [10] used microwave radiation to detoxify sediment sludge by microwave heating, drying and metal ion immobilization within sediment solids. If just raw, wet sludge was treated in a microwave; the samples would be only dried. However, if the sludge is mixed with a little suitable microwave absorber (such as $\mathrm{C}$ ), then a temperature of $900^{\circ} \mathrm{C}$ can be obtained, so pyrolysis, rather than drying, occurs [11]. Moreover, the microwave drying of sludge, which reduces the volume and mass of the sludge is important in reducing the cost of its disposal [12]. Weian [13] performed the microwave-assisted acidic ferric chloride leaching of a copper sulfide concentrate and found that microwave-assisted leaching accelerated the dissolution of copper. All of these previous investigations examined the drying, heating and digesting of samples. Instances of the use of microwaves to remove metals from industrial sludge and comparisons of microwave-assisted and traditional acid extraction are few in the literature. Hence, this study applies sulfuric and nitric acids to remove copper from industrial sludge by microwaveassisted and traditional acid extraction. The effects of sludge particle size, acid concentration, extraction time, S/L ratio and microwave power on the copper removal efficiency were examined. Haque [6] showed that added carbon could accelerate microwave heating. Therefore, this work further evaluated the effect of adding carbon on microwave-enhanced extraction.

The composition of the industrial sludge importantly governs extraction behavior. The use of the total concentration of the metals in the sludge with respect to leaching implies that all forms of a given metal are equally soluble; such an assumption is untenable. A sequential extraction procedure can help to characterize the leaching behavior by dividing all the metal into fractions. Of the various sequential extraction methods available, the one used most often is that developed by Tessier et al. [14]. As determined by the procedure developed by Tessier et al. [14], heavy metals are associated with five fractions - the exchangeable fraction, which is likely to be affected by changes in the ionic composition of water as well as in the sorption-desorption processes; the carbonate fraction, which is sensitive to changes in $\mathrm{pH}$; the reducible fraction, which includes iron and manganese oxides that are thermodynamically unstable under anoxic conditions; the organic fraction, which can be oxidizing, thereby releasing soluble metals under appropriate conditions; the residual fraction, which may retain metals in a crystalline structure [15]. High proportions of exchangeable and carbonate fractions enable metals to be easily removed from the sludge. In contrast, high percentages of $\mathrm{Fe}-\mathrm{Mn}$ oxides, organic matter and residual fractions tended to fix the metals in the sludge, which was therefore stable. Su and Wong [16] established that the proportions of $\mathrm{Cu}, \mathrm{Zn}$ and $\mathrm{Ni}$ in the residual fraction increased with the rate of fly ash amendment in sewage sludge. In their work, most $\mathrm{Cu}$ was associated with organic matter, but $\mathrm{Zn}$ and $\mathrm{Ni}$ were in $\mathrm{Fe}-\mathrm{Mn}$ oxide and residual forms [16]. Ammonia solution leaching markedly changed the fractionation, reducing the amounts of organic matter and $\mathrm{Fe}-\mathrm{Mn}$ oxide-bound copper; however, the carbonate-bound fraction of copper increased [17]. The metals were mobilized into more stable fractions as the treatment temperature increased [18]. All previous investigations have shown that various treatments cause shifting among metal fractions. The distribution of heavy metals among these five fractions by sequential extraction determines the potential mobility of heavy metals in industrial sludge before and after acid extraction.

The goals of this study are: (i) to study the removal efficiency of copper by traditional and microwave-assisted acid extraction, (ii) to elucidate the effect of sludge particle size, acid concentration, extraction time, $\mathrm{S} / \mathrm{L}$ ratio and microwave power on copper removal efficiency, (iii) to evaluate the effect of adding carbon on microwave-enhanced acid extraction and (iv) to identify the metal partitions that remain in the residue after various acid extraction treatments.

\section{Materials and methods}

\subsection{Characteristics of industrial sludge}

Industrial sludge was obtained from a printed circuit board plant in Tao-Yuan County, Taiwan. A $20 \mathrm{~g}$ sample of sludge was mixed with $20 \mathrm{ml}$ deionized water for $5 \mathrm{~min}$. The sample was centrifuged and filtered through a $0.45 \mu \mathrm{m}$ membrane filter, and the acidity of the filtrate was measured using a $\mathrm{pH}$ meter. The quantity of heavy metals in the industrial sludge was determined after it was digested in aqua regia, which is a mixture of concentrated $\mathrm{HCl}$ and concentrated $\mathrm{HNO}_{3}$ ( $\mathrm{HCl}: \mathrm{HNO}_{3}=1: 3$ ). The suspension was cooled and filtered through a $0.45 \mu \mathrm{m}$ membrane filter and the filtrate was analyzed to identify the presence of $\mathrm{Cu}, \mathrm{Ni}, \mathrm{Pb}$ and $\mathrm{Zn}$ using inductively coupled plasma (ICP) spectrometry. The $\mathrm{pH}$ and the 
Table 1

Conditions of traditional acid extraction for various extraction procedures

\begin{tabular}{|c|c|c|c|c|}
\hline Conditions & TCLP & MTCLP & ANC & MANC \\
\hline Sludge (g) & 50 & 5 & 5 & 5 \\
\hline Particle size & $<9.5 \mathrm{~mm}$ & $<9.5 \mathrm{~mm}$ & $<150 \mu \mathrm{m}$ & $<150 \mu \mathrm{m}$ \\
\hline $\mathrm{S} / \mathrm{L}$ ratio & $1 / 20$ & $1 / 20$ & $1 / 6$ & $1 / 6$ \\
\hline Extractant & Acetic acid & Nitric acid, sulfuric acid & Nitric acid & Nitric acid, sulfuric acid \\
\hline Concentration $(\mathrm{N})$ & 0.1 & $0.1,0.5,1.0,1.5,2.0$ & Not defined & $0.2,0.4,0.6,0.8,1.0$ \\
\hline Time & $18 \mathrm{~h}$ & $5,30,60,90,120,150,180 \mathrm{~min}$ & $48 \mathrm{~h}$ & $1,2,3,4,6,9,12,18,24,36,48 \mathrm{~h}$ \\
\hline Mixing (rpm) & 30 & 30 & Not defined & 30 \\
\hline
\end{tabular}

heavy metal contents were measured in triplicate. The crystallinity of the raw sludge was elucidated by X-ray diffraction (XRD). The raw sludge was examined by scanning electron microscopy (SEM) using a LEO 1530.

\subsection{Traditional and microwave acid extraction}

The sludge was oven-dried at $105^{\circ} \mathrm{C}$ until a constant mass was reached. Thereafter, the dried sludge was ground, and the sample was sieved to yield particles of sizes $d<9.5 \mathrm{~mm}$ and $d<150 \mu \mathrm{m}$. The acid neutralization capacity (ANC) procedure and the toxicity characteristic leaching procedure (TCLP) were modified to extract $\mathrm{Cu}$ from the industrial sludge, to determine the removal efficiency of $\mathrm{Cu}$. The extractant of TCLP and ANC was acetic acid and nitric acid and the extraction time of TCLP and ANC was 18 and $48 \mathrm{~h}$, respectively. Table 1 presents in detail the conditions of the procedures. Copper removal efficiencies using various acids at various concentrations were compared. Following each extraction, all of the suspensions were centrifuged and the supernatants were filtered through a $0.45 \mu \mathrm{m}$ membrane filter. The filtrate was acidified to $\mathrm{pH}<2$ before it was analyzed to determine the concentrations of heavy metals. The concentration of each heavy metal was measured by ICP. The kinetics of extraction from industrial sludge was elucidated using nitric acid and sulfuric acid at $1 \mathrm{~N}$ and all other conditions were as stated in Table 1.

A domestic microwave oven (BERGHOF MWS-2, $1000 \mathrm{~W}, 2.45 \mathrm{GHz}$ ) was used as the microwave radiation source. Table 2 lists the experimental conditions for the microwave-assisted and microwave-enhanced acid extraction. The samples were treated and analyzed in a manner similar to the traditional acid extraction scheme.

Table 2

Conditions of microwave acid extraction for various extraction procedures

\begin{tabular}{lll}
\hline Conditions & Microwave-assisted & Microwave-enhanced \\
\hline Sludge $(\mathrm{g})$ & 5 & 5 \\
Particle size & $<9.5 \mathrm{~mm},<150 \mu \mathrm{m}$ & $<9.5 \mathrm{~mm},<150 \mu \mathrm{m}$ \\
S/L ratio & $1 / 6,1 / 20$ & $1 / 6,1 / 20$ \\
Sludge/active carbon & - & $1 / 1$ \\
Extractant & Nitric acid, sulfuric & Sulfuric acid \\
& acid & \\
Concentration $(\mathrm{N})$ & 1.0 & 1.0 \\
Time (min) & $3,4,5,10,20,30$ & $3,4,5,10,20,30$ \\
Microwave power $(\mathrm{W})$ & $400,600,800$ & 800 \\
\hline
\end{tabular}

Table 3

Experimental conditions of sequential extraction

\begin{tabular}{|c|c|}
\hline Partitions & Agents and procedures \\
\hline Exchangeable (weakly adsorbed) & $8 \mathrm{ml} 1 \mathrm{M} \mathrm{MgCl}_{2}, \mathrm{pH} 7.0(1 \mathrm{~h})$ \\
\hline Carbonate-bound (acid soluble) & $8 \mathrm{ml} 1 \mathrm{M} \mathrm{NaOAc}, \mathrm{pH} 5.0(5 \mathrm{~h})$ \\
\hline Fe-Mn oxides-bound (reducible) & $\begin{array}{l}20 \mathrm{ml} 0.04 \mathrm{M} \mathrm{NH}_{2} \mathrm{OH} \cdot \mathrm{HCl} \\
96^{\circ} \mathrm{C}(5 \mathrm{~h})\end{array}$ \\
\hline Organic matter-bound (oxidizable) & $\begin{array}{l}3 \mathrm{ml} \quad 0.02 \mathrm{M} \mathrm{HNO}_{3} / 5 \mathrm{ml} 30 \% \\
\mathrm{H}_{2} \mathrm{O}_{2}, 85^{\circ} \mathrm{C}(3 \mathrm{~h}) \text {, after cooling } \\
5 \mathrm{ml}, 3.2 \mathrm{M} \mathrm{NH}_{4} \mathrm{OAc}(30 \mathrm{~min})\end{array}$ \\
\hline $\begin{array}{l}\text { Residual bound (silicates and } \\
\text { unreactive oxides) }\end{array}$ & $10 \mathrm{ml} 97 \% \mathrm{H}_{2} \mathrm{SO}_{4}(1 \mathrm{~h})$ \\
\hline
\end{tabular}

\subsection{Sequential extraction}

Metal speciation of the raw and extracted sludge samples was performed by five-stage sequential extraction, following the procedure of Tessier et al. [14]. Table 3 summarizes the steps and the operationally defined fractions of the metals. The sequential extractions were conducted on $5 \mathrm{~g}$ of dried industrial sludge. Following each step of the extraction, all of the suspensions were centrifuged and the supernatants were filtered through a $0.45 \mu \mathrm{m}$ membrane filter. The filtrate was acidified to $\mathrm{pH}<2$ before it was analyzed to identify heavy metals. The residues were washed with deionized water; after it was centrifuged, the solution thus obtained was discarded, and the next extraction agent was added. The concentration of copper was also measured using ICP. The percentage of copper recovered from different extraction systems was determined as follows:

Recovery $(\%)=[\mathrm{CSE}] /[\mathrm{TMC}] \times 100$

where [CSE] stands for the total concentration of copper in each partition of raw or extracted sludge, as determined by sequential extraction procedures. [TMC] is the total concentration of copper of raw or extracted industrial sludge.

\section{Results and discussion}

\subsection{Properties of the raw industrial sludge}

The $\mathrm{pH}$ of the industrial sludge was 6.5 and the moisture content was $48.7 \%$. The metal sludge was analyzed using ICP, which revealed that the total amounts of metals $\mathrm{Cu}, \mathrm{Ni}$, $\mathrm{Pb}$ and $\mathrm{Zn}$ in the sludge were $71.9,0.9,1.3$ and $0.7 \mathrm{mg} / \mathrm{g}$, 


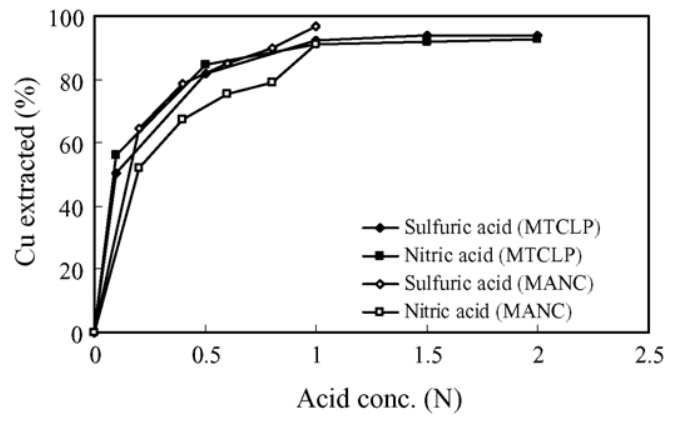

Fig. 1. Efficiency of acid extraction using various concentrations of sulfuric and nitric acids (with MTCLP and MANC extraction times of 18 and $48 \mathrm{~h}$ ).

respectively. Concentrations were expressed in terms of dry mass. A high $\mathrm{Cu}$ concentration rendered the industrial sludge hazardous. Given the highest content of $\mathrm{Cu}$ in the sludge, $\mathrm{Cu}$ was used as the target metal to be removed. The efficiency of removal depended on the partitions of the heavy metal and the $\mathrm{pH}$ of the sludge. The crystal structures of the raw industrial sludge were analyzed by XRD and the results indicated that the sludge was amorphous and no crystal form could be identified. The SEM analysis revealed that the sludge comprised irregularly shaped aggregated small particles with diameters of approximately $20-30 \mu \mathrm{m}$.

\subsection{Traditional acid extraction}

Fig. 1 plots the efficiency of extraction of copper using various concentrations of sulfuric and nitric acids by modified ANC (MANC) and modified TCLP (MTCLP) methods. The MANC procedures were applied to smaller sludge particles with a higher S/L ratio than MTCLP to elucidate the effects of the sludge particle size and $\mathrm{S} / \mathrm{L}$ ratio. The results were expressed as the amount of copper extracted as a percentage of the original amount of content. The results are compared to those of acid treatment. About $1 \mathrm{~N}$ acid was required to extract large quantities of copper, and the extraction efficiencies of sulfuric acid (MTCLP), sulfuric acid (MANC), nitric acid (MTCLP) and nitric acid (MANC) were 92, 97, 91 and 91\%, respectively. The percentage of copper extracted increased with the acid concentration, and the dependence between the extracted efficiency and the acid concentration was strong when the acid concentration was less than $1 \mathrm{~N}$. The mechanisms of the retention of heavy metals in sludge involve: (i) the adsorption onto suspended solids and (ii) presence as hydroxide precipitates; the latter is the dominant mechanism. At low $\mathrm{pH}$, heavy metals adsorbed onto the solid phase are exchanged with high concentrations of protons and heavy metal hydroxides are dissolved. The metals are accordingly removed from the industrial sludge. Several investigations have shown the effectiveness of strong acids in extracting metals from sludge and slag $[1,2,4,19]$ and that higher concentrations of acid leaching correspond to greater heavy metal content from slag and sludge [4,5,19-21]. However, Fig. 1 does not clearly depict the effects of the sludge
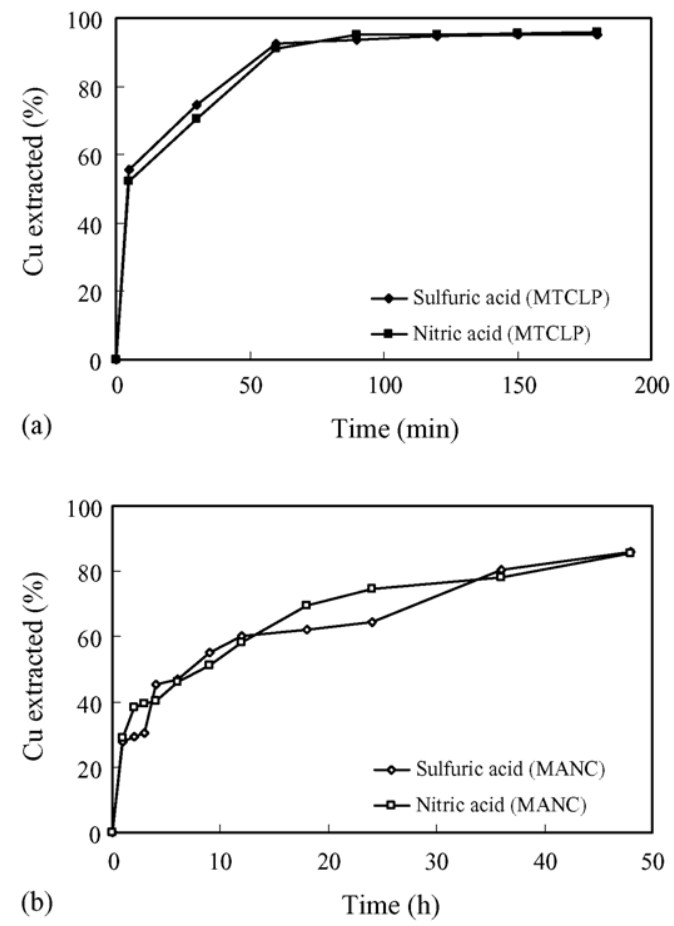

Fig. 2. Acid extraction efficiency as a function of time using $1 \mathrm{~N}$ sulfuric and nitric acids: (a) MTCLP and (b) MANC.

particle size or the S/L ratio on the efficiency of copper extraction. The extraction times associated with MTCLP and MANC differed. So the kinetics of traditional acid extraction must be further examined to determine the effects of these factors.

Fig. 2 plots the kinetics of extraction using $1 \mathrm{~N}$ sulfuric and nitric acids by MTCLP and MANC. The extraction of Cu by nitric and sulfuric acids exhibited a lag after $60 \mathrm{~min}$ in MTCLP; however, extraction by these acids in MANC increased with extraction time. For a given extraction time, $60 \mathrm{~min}$, the percentages of copper extracted using sulfuric acid (MTCLP), sulfuric acid (MANC), nitric acid (MTCLP) and nitric acid (MANC) were 92, 28, 91 and 29\%, respectively.

The extraction rate constants $(k)$ of $\mathrm{Cu}$ using various traditional acid extraction systems were determined by first-order kinetics, and the $k$ values of sulfuric acid (MTCLP), sulfuric acid (MANC), nitric acid (MTCLP) and nitric acid (MANC) were $0.372,0.022,0.426$ and $0.020 \mathrm{~h}^{-1}$, respectively. The rates of extraction of MTCLP in both $1 \mathrm{~N}$ sulfuric and nitric acids were 10 times higher than those of MANC. In practical situations, a shorter extraction period can be obtained using a smaller reactor, reducing the associated capital and operating costs. Figs. 1 and 2 reveal that the percentage of copper extracted increased with the acid concentration and the contact time, because increasing the acid concentration and the contact time increases the energy available to break the chemical bonds of the metals in the sludge [19]. MTCLP is more economic than MANC, because of its high extraction percentage and high extraction rate, and the associated adaptive extraction time of approximately $60 \mathrm{~min}$. 
MTCLP was applied to larger sludge particles than MANC; so the experimental results indicate that extraction from coarse sludge particle $(d<9.5 \mathrm{~mm})$ could be undertaken by nitric acid and that from fine sludge particles $(d<150 \mu \mathrm{m})$ could be conducted using sulfuric acid. Under the same experimental conditions, copper in fine particles is known to be extracted more quickly than that in coarse particles of sludge. The $k$ value of MTCLP exceeded that of MANC, and the sludge particles to which MANC was applied were smaller than those associated with MTCLP. These facts reveal that the $\mathrm{S} / \mathrm{L}$ ratio dominated traditional acid extraction, and the extraction rate increased as the $\mathrm{S} / \mathrm{L}$ ratio declined. Restated, adding more acid increased the extraction rate from coarse sludge particles. Li et al. [22] established that the extracted $\mathrm{Ca}$ concentration at $\mathrm{S} / \mathrm{L}$ ratios of $1 / 8$ and $1 / 16$ was 35.4 and $62.9 \mathrm{mg} / \mathrm{g}$. However, Chang and Liu [17] and Xia and Pickles [7] stated that the metal recovery increased with the S/L ratio.

\subsection{Microwave acid extraction}

Based on the results of traditional acid extraction, $1 \mathrm{~N}$ sulfuric and nitric acids were used in tests of microwave-assisted and microwave-enhanced acid extraction. Fig. 3 depicts the extent of microwave-assisted sulfuric acid extraction at various microwave powers, sludge particle sizes and $\mathrm{S} / \mathrm{L}$ ratios. The copper extraction efficiency increased sharply during the first $10 \mathrm{~min}$, and reached an equilibrium after about $20 \mathrm{~min}$,
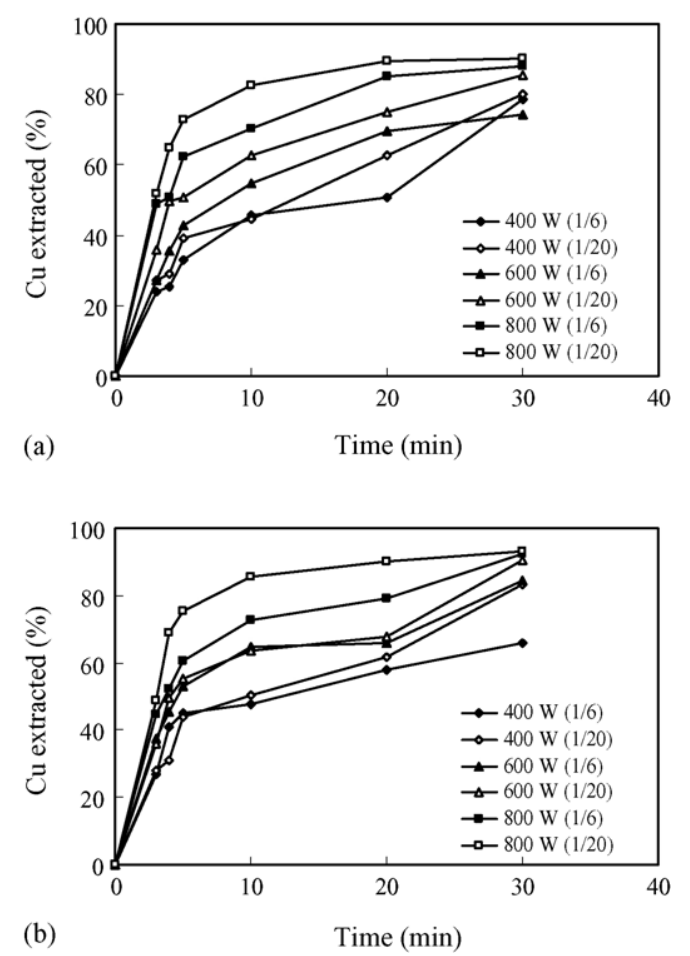

Fig. 3. Efficiency of microwave/sulfuric acid extraction at various power values and S/L ratios: (a) coarse particles $(d<9.5 \mathrm{~mm})$ and (b) fine particles $(d<150 \mu \mathrm{m})($ sulfuric acid $=1 \mathrm{~N})$. at which point, the percentages of copper extracted from the coarse sludge particles at $800 \mathrm{~W}(1 / 20), 800 \mathrm{~W}(1 / 6), 600 \mathrm{~W}$ $(1 / 20), 600 \mathrm{~W}(1 / 6), 400 \mathrm{~W}(1 / 20)$ and $400 \mathrm{~W}(1 / 6)$ using $1 \mathrm{~N}$ sulfuric acid were $89,85,75,70,63$ and $51 \%$, respectively, and those from fine sludge particles were 90, 79, 68, 66, 62 and $58 \%$, respectively. A higher microwave power and lower $\mathrm{S} / \mathrm{L}$ ratio corresponded to more efficient copper extraction; however, the effect of the size of the sludge particles was insignificant (Fig. 3). The results of microwave-assisted acid extraction indicated once again that the $\mathrm{S} / \mathrm{L}$ ratio was the most important factor in the removal of copper from industrial sludge. This finding was similar to that for traditional acid extraction.

Fig. 4 presents microwave-assisted nitric acid extraction at various microwave powers, sludge particle sizes and S/L ratios. The results of sulfuric and nitric acids in microwaveassisted acid extraction were similar. In both cases, higher microwave power and lower $\mathrm{S} / \mathrm{L}$ ratio corresponded to more efficient extraction of copper (Figs. 3 and 4). At an S/L ratio of $1 / 20,80 \%$ of copper was extracted after 60 and $20 \mathrm{~min}$ of traditional and microwave-assisted $(800 \mathrm{~W}) \mathrm{ex}-$ traction, respectively; however, at an $\mathrm{S} / \mathrm{L}$ ratio of $1 / 6,80 \%$ of copper was extracted after $36 \mathrm{~h}$ and $20 \mathrm{~min}$ of traditional and microwave-assisted acid extraction, respectively. The microwave energy reduced the extraction time and the effect in the larger S/L ratio was more significant. Weian [13] also stated that microwave-assisted leaching provided faster dissolution of copper, whose finding was consistent with that obtained herein.
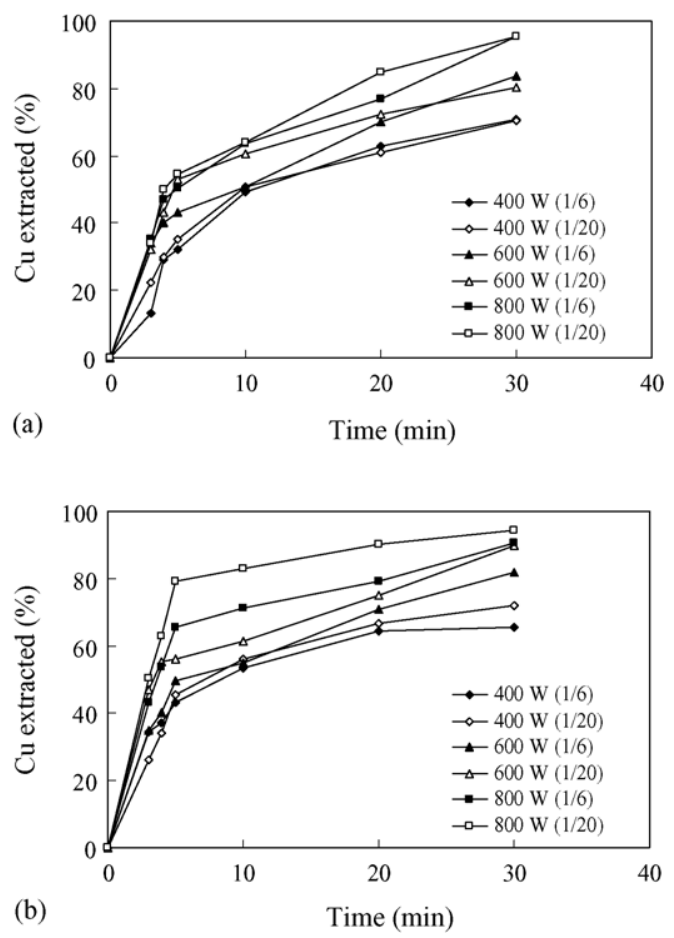

Fig. 4. Efficiency of microwave/nitric acid extraction at various power values and S/L ratios: (a) coarse particles $(d<9.5 \mathrm{~mm})$ and (b) fine particles $(d<150 \mu \mathrm{m})($ nitric $\operatorname{acid}=1 \mathrm{~N})$. 

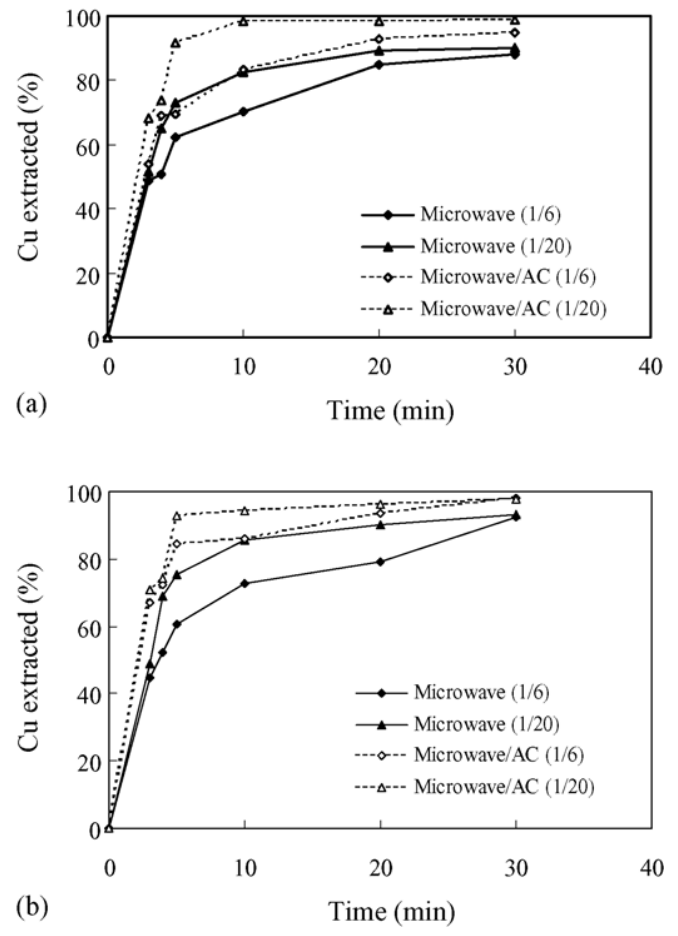

Fig. 5. Increase in microwave/sulfuric acid/active carbon extraction efficiency at various power values and S/L ratios: (a) coarse particles $(d<9.5 \mathrm{~mm})$ and (b) fine particles $(d<150 \mu \mathrm{m})$ (sulfuric acid concentration $=1 \mathrm{~N}$, power $=800 \mathrm{~W}$ and sludge/active carbon $=1)$.

Haque [6] demonstrated that added carbon can accelerate microwave heating and Chang and Liu [17] showed that increasing the temperature promotes the leaching reaction. Therefore, active carbon was added to evaluate the promotion of microwave-assisted acid extraction. Fig. 5 plots the results of microwave/sulfuric acid $(1 \mathrm{~N}) /$ active carbon enhancedextraction at $800 \mathrm{~W}$. At an $\mathrm{S} / \mathrm{L}$ ratio of $1 / 6$ or $1 / 20$, adding active carbon reduced the time required to extract $80 \%$ of copper from 20 to $10 \mathrm{~min}$. The results agreed with those in earlier works $[6,17]$, which have found that adding carbon accelerated heating and increasing the temperature accelerated the extraction.

The rate of copper extraction reached a maximum during the first $5 \mathrm{~min}$ of the reaction; a higher microwave power and a lower $\mathrm{S} / \mathrm{L}$ ratio corresponded to a higher rate of extraction of copper. Also the lower S/L ratio might induce a higher extracted rate; however, the addition of active carbon in the higher $\mathrm{S} / \mathrm{L}$ ratio system indicated a higher extracted rate than that in the lower $\mathrm{S} / \mathrm{L}$ ratio system. These experimental findings demonstrate that the most important factors in microwave acid extraction were the addition of a microwave absorber, the microwave power input, and the $\mathrm{S} / \mathrm{L}$ ratio, in that order. The size of the sludge particles did not significantly affect the extraction of copper. Microwave acid extraction is more expensive than traditional acid extraction; however, the efficiency of the microwave acid extraction of copper greatly exceeded that of traditional acid extraction.

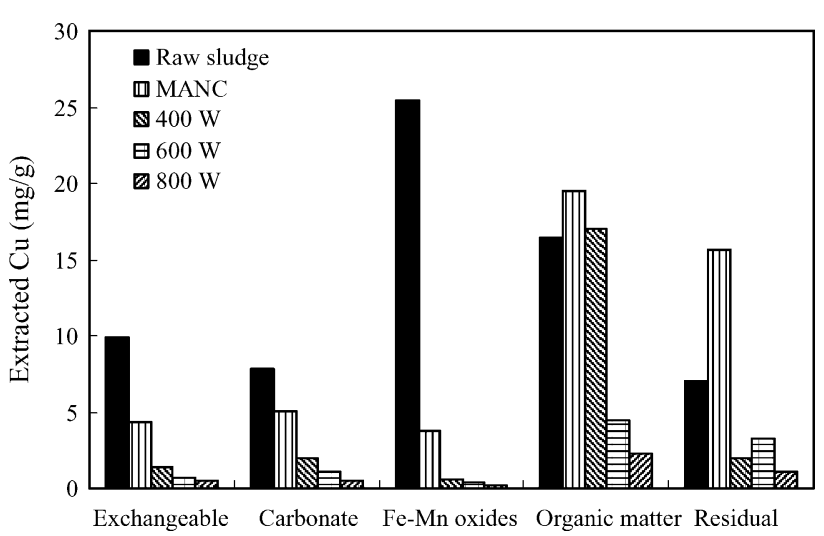

Fig. 6. Amounts of $\mathrm{Cu}$ that are extractable from different fractions of various sulfuric acid extraction systems using sequential extraction procedures ( sulfuric acid concentration $=1 \mathrm{~N}$, extraction time $=30 \mathrm{~min}, \mathrm{~S} / \mathrm{L}$ ratio $=1 / 6$ and particle size $<150 \mu \mathrm{m})$.

\subsection{Partition of copper by sequential extraction}

The sequential extraction procedure elucidates the form of copper in the industrial sludge. Herck and Vandecasteele [23] revealed that sequential extraction can be used only for qualitative, and not quantitative, analysis. Nyamangara [24] demonstrated that the results of sequential extraction provide only an overall appreciation of the factors that influence metal release and do not yield accurate values of the percentages of various forms of metal. However, the dominant form of copper in sludge varies among the literature. Fig. 6 plots the quantities of copper in various forms in the raw industrial sludge and in the residue after various extraction procedures. Table 4 presents the corresponding amount and percentage of extractable $\mathrm{Cu}$ and the ratio of recovery associated with extraction procedures. Unlike for raw sludge, all residues were extracted using $1 \mathrm{~N}$ sulfuric acid for $30 \mathrm{~min}$, with particle size $<150 \mu \mathrm{m}$ and $\mathrm{S} / \mathrm{L}$ ratio $=1 / 6$. The largest fraction of $\mathrm{Cu}$ in raw sludge was bound to $\mathrm{Fe}-\mathrm{Mn}$ oxides $(25.5 \mathrm{mg} / \mathrm{g})$. The exchangeable and carbonate fractions, sensitive to changes in ionic strength and $\mathrm{pH}$, represented approximately 14 and 12\% of the total $\mathrm{Cu}$ content. The high percentage associated with the exchangeable and carbonate fractions reveal that metals could be easily removed from such industrial sludge by acid extraction. Alvarez et al. [25] indicated that there were higher levels of oxidizable copper compared to the other forms in all types of wastewater treatment plants. Hsiau and Lo [26] also showed that most copper in sewage sludge was bound to organic matter $(73.7 \%)$. Most of the native copper in sewage sludge was in residual (45\%) and organic (30\%) forms [24]. Oxidizable and residual fractions together represented $95 \%$ of the total copper content in aerobic and anaerobic sludges, suggesting that copper was associated with strong organic ligands and probably occluded in minerals [27]. Chang and Liu [17] indicated that residual copper was dominant (42.3\%) in industrial sludge, while both $\mathrm{Fe}-\mathrm{Mn}$ oxide-bound (33.8\%) and carbonate-bound (23.7\%) forms of copper were also present. This fact might follow from the use of various 
Table 4

Amount and percentage of $\mathrm{Cu}$ that is extractable from various fractions in different systems using sequential extraction procedures

\begin{tabular}{|c|c|c|c|c|c|c|c|c|c|c|}
\hline & \multicolumn{2}{|c|}{ Raw sludge } & \multicolumn{2}{|c|}{$\mathrm{MANC}^{\mathrm{a}}$} & \multicolumn{2}{|c|}{$400 \mathrm{~W}^{\mathrm{a}}$} & \multicolumn{2}{|c|}{$600 \mathrm{~W}^{\mathrm{a}}$} & \multicolumn{2}{|c|}{$800 \mathrm{~W}^{\mathrm{a}}$} \\
\hline & $\mathrm{mg} / \mathrm{g}$ & $\%$ & $\mathrm{mg} / \mathrm{g}$ & $\%$ & $\mathrm{mg} / \mathrm{g}$ & $\%$ & $\mathrm{mg} / \mathrm{g}$ & $\%$ & $\mathrm{mg} / \mathrm{g}$ & $\%$ \\
\hline Exchangeable & 9.9 & 14 & 4.4 & 9 & 1.4 & 6 & 0.7 & 7 & 0.5 & 11 \\
\hline Carbonate & 7.8 & 12 & 5.0 & 10 & 2.0 & 9 & 1.1 & 11 & 0.5 & 11 \\
\hline Fe-Mn oxides & 25.5 & 38 & 3.8 & 8 & 0.6 & 2 & 0.4 & 4 & 0.2 & 4 \\
\hline Organic matter & 16.5 & 25 & 19.5 & 41 & 17.0 & 74 & 4.5 & 45 & 2.3 & 50 \\
\hline Residual & 7.1 & 11 & 15.7 & 32 & 2.0 & 9 & 3.3 & 33 & 1.1 & 24 \\
\hline Recovery (\%) & & 93 & & 90 & & 94 & & 93 & & 85 \\
\hline
\end{tabular}

a System conditions: sulfuric acid $=1 \mathrm{~N}$, extraction time $=30 \mathrm{~min}, \mathrm{~S} / \mathrm{L}$ ratio $=1 / 6$ and particle size $<150 \mu \mathrm{m}$.

sources of sludge, the use of various agents and the variation among sequential extraction conditions. In this work, the copper partition of raw sludge followed the order Fe-Mn oxides $>$ organic matter $>$ exchangeable $\approx$ carbonate $\approx$ residual bound (Table 4).

The recovery ratios of $\mathrm{Cu}$ in raw sludge with MANC for microwave-assisted extraction at 400, 600 and $800 \mathrm{~W}$ were 93, 90, 94, 93 and $85 \%$ (Table 4). The results are quite consistent despite the errors that may arise during sequential extraction. Small amounts of solids are removed by the supernatant, possibly reducing the copper concentration as described below, yielding a recovery ratio of less than $100 \%$.

Most of the $\mathrm{Cu}$ extracted by sludge is bound to organic matter, regardless of the extraction system used (Table 4). The proportions of copper in the organic matter and residual fractions increased markedly whereas those in the Fe-Mn oxides, exchangeable and carbonate fractions declined considerably during traditional and microwave-assisted sulfuric acid extraction (Fig. 6). These results imply that the extracted sludge was more stable than the raw industrial sludge.

This work employed traditional and microwave-assisted acid extraction to remove copper from industrial sludge; the results revealed that sulfuric acid was an effective extractant and that the most of the copper extracted from the sludge shifted from being bound to the Fe-Mn oxides and organic matter to being bound to organic matter and being residual. Naoum et al. [19] also showed that most of the copper in the sludge residue after acid treatment was in organic $(67.5 \%)$ and residual $(12.5 \%)$ forms. Restated, the extracted sludge was more stable than the raw sludge, which was similar to the result of previous investigations [17-19].

\section{Conclusions}

Traditional and microwave acid extractions were adopted to evaluate the efficiency of copper removal from industrial sludge. The percentage of extraction of copper increased with the acid concentration, and the dependence of the efficiency of traditional acid extraction on the acid concentration was strong at acid concentrations of below 1N. After an extraction period of $60 \mathrm{~min}$, the percentages of copper extracted using sulfuric acid (MTCLP), sulfuric acid (MANC), nitric acid (MTCLP) and nitric acid (MANC) were 92, 28, 91 and $29 \%$, respectively. The extraction rate constants $(k)$ associated with sulfuric acid (MTCLP), sulfuric acid (MANC), nitric acid (MTCLP) and nitric acid (MANC) were 0.372, $0.022,0.426$ and $0.020 \mathrm{~h}^{-1}$, respectively. The experimental results of traditional acid extraction reveal that nitric acid was most effective for extraction from coarse sludge particles $(d<9.5 \mathrm{~mm})$ and sulfuric acid was most effective for extraction from fine sludge particles $(d<150 \mu \mathrm{m})$. The copper extraction efficiency of microwave acid extraction increased sharply in the first $10 \mathrm{~min}$, reaching equilibrium after approximately $20 \mathrm{~min}$ of the reaction. Higher microwave power and the lower $\mathrm{S} / \mathrm{L}$ ratio corresponded to more efficient copper extraction. The effect of sludge particle size was insignificant for both traditional and microwave acid extraction systems. Carbon addition promoted extraction and shortened extraction time. These experimental findings demonstrated that the most important factors in microwave acid extraction were the addition of microwave absorber and the input microwave power, followed by the $\mathrm{S} / \mathrm{L}$ ratio. The forms of copper in raw sludge followed the order $\mathrm{Fe}-\mathrm{Mn}$ oxides $>$ organic matter $>$ exchangeable $\approx$ carbonate $\approx$ residual bound. The extracted sludge of different extraction systems all showed that the most copper partition was organic matter bound.

\section{Acknowledgement}

The authors would like to thank the Ministry of Economic Affairs of the Republic of China for financially supporting this research under Contract No. 92-EC-17-A-10-S1-0007.

\section{References}

[1] C.Q. Jia, J.Z. Xiao, R.G. Orr, Behaviour of metals in discard nickel smelter slag upon reacting with sulfuric acid, J. Environ. Sci. Health A 34 (1999) 1013-1034.

[2] C. Arslan, F. Arslan, Recovery of copper, cobalt, and zinc from copper smelter and converter slags, Hydrometallurgy 67 (2002) 1-7. 
[3] A.N. Banza, E. Gock, K. Kongolo, Base metals recovery from copper smelter slag by oxidizing leaching and solvent extraction, Hydrometallurgy 67 (2002) 63-69.

[4] C.H. Wu, C.Y. Kuo, S.L. Lo, Removal of metals from industrial sludge by extraction with different acids, J. Environ. Sci. Health A 39 (2004) 2205-2219.

[5] I.B. Ahmed, P.K. Gbor, C.Q. Jia, Aqueous sulphur dioxide leaching of $\mathrm{Cu}, \mathrm{Ni}, \mathrm{Co}, \mathrm{Zn}$ and $\mathrm{Fe}$ from smelter slag in absence of oxygen, Can. J. Chem. Eng. 78 (2000) 694-703.

[6] K.E. Haque, Microwave energy for mineral treatment processes-a brief review, Int. J. Miner. Process 57 (1999) 1-24.

[7] D.K. Xia, C.A. Pickles, Microwave caustic leaching of electric arc furnace dust, Miner. Eng. 13 (2000) 79-94.

[8] B. Perez-Cid, I. Lavilla, C. Bendicho, Application of microwave extraction for partitioning of heavy metals in sewage sludge, Anal. Chim. Acta 378 (1999) 201-210.

[9] V. Sandroni, C.M.M. Smith, Microwave digestion of sludge, soil and sediment samples for metal analysis by inductively coupled plasma-atomic emission spectrometry, Anal. Chim. Acta 468 (2002) 335-344.

[10] Q. Gan, A case study of microwave processing of metal hydroxide sediment sludge from printed circuit board manufacturing wash water, Waste Manage. 20 (2000) 695-701.

[11] J.A. Menendez, M. Inguanzo, J.J. Pis, Microwave-induced pyrolysis of sewage sludge, Water Res. 36 (2002) 3261-3264.

[12] A. Idris, K. Khalid, W. Omar, Drying of silica sludge using microwave heating, Appl. Therm. Eng. 24 (2004) 905-918.

[13] D. Weian, Leaching behavior of complex sulphide concentrate with ferric chloride by microwave irradiation, Rare Met. 16 (1997) $152-155$.

[14] A. Tessier, P.C. Campbell, M. Bisson, Sequential extraction procedure for the speciation of particulate trace metals, Anal. Chem. 51 (1979) 844-851.

[15] A.A. Zorpas, T. Constantinides, A.G. Vlyssides, I. Haralambous, M. Loizidou, Heavy metal uptake by natural zeolite and metals partitioning in sewage sludge compost, Biores. Technol. 72 (2000) 113-119.
[16] D.C. Su, J.W.C. Wong, Chemical speciation and phytoavailability of $\mathrm{Zn}, \mathrm{Cu}, \mathrm{Ni}$ and $\mathrm{Cd}$ in soil amended with fly ash-stabilized sewage sludge, Environ. Int. 29 (2003) 895-900.

[17] C.J. Chang, J.C. Liu, Feasibility of copper leaching from an industrial sludge using ammonia solutions, J. Hazard. Mater. 58 (1998) $121-132$.

[18] A.A. Zorpas, A.G. Vlyssides, G.A. Zorpas, P.K. Karlis, D. Arapoglou, Impact of thermal treatment on metal in sewage sludge from the Psittalias wastewater treatment plant, Athens, Greece, J. Hazard. Mater. 82 (2001) 291-298.

[19] C. Naoum, D. Fatta, K.J. Haralambous, M. Loizidou, Removal of heavy metals from sewage sludge by acid treatment, J. Environ. Sci. Health A 36 (2001) 873-881.

[20] K.J. Hong, S. Tokunaga, T. Kajiuchi, Extraction of heavy metals from MSW incinerator fly ashes by chelating agents, J. Hazard. Mater. 75 (2000) 57-73.

[21] F.K.M. Kazi, P.A. Cooper, Rapid-extraction oxidation process to recover and reuse copper chromium and arsenic from industrial wood preservative sludge, Waste Manage. 22 (2002) 293-301.

[22] X.D. Li, C.S. Poon, H. Sun, I.M.C. Lo, D.W. Kirk, Heavy metal speciation and leaching behaviors in cement based solidified/stabilized waste materials, J. Hazard. Mater. 82 (2001) 215-230.

[23] P.V. Herck, C. Vandecasteele, Evaluation of the use of a sequential extraction procedure for the characterization and treatment of metal containing solid waste, Waste Manage. 21 (2001) 685-694.

[24] J. Nyamangara, Use of sequential extraction to evaluate zinc and copper in a soil amended with sewage sludge and inorganic metal salts, Agric. Ecosyst. Environ. 69 (1998) 135-141.

[25] E.A. Alvarez, M.C. Mochon, J.C.J. Sanchez, M.T. Rodriguez, Heavy metal extractable forms in sludge from wastewater treatment plants, Chemosphere 47 (2002) 765-775.

[26] P.C. Hsiau, S.L. Lo, Fractionation and leachability of $\mathrm{Cu}$ in limetreated sewage sludge, Water Res. 32 (1998) 1103-1108.

[27] A. Fuentes, M. Llorens, J. Saez, A. Soler, M.I. Aguilar, J.F. Ortuno, V.F. Meseguer, Simple and sequential extractions of heavy metals from different sewage sludges, Chemosphere 54 (2004) 1039-1047. 